\title{
The Relationship between Field Independence/ Dependence Styles and Reading Comprehension Abilities of EFL Readers
}

\author{
Masoud Khalili Sabet \\ English Department, University of Guilan, Rasht, Iran \\ Shahrbanoo Mohammadi (Corresponding author) \\ English Department, University of Guilan, Rasht, Iran
}

\begin{abstract}
The present study intends to investigate the relationship between Field Independence/Dependence styles and reading comprehension abilities of intermediate EFL readers as well as to explore their attitude toward reading in a foreign language with respect to their cognitive style. To these aims, ninety university students took part in the study. First, for the purpose of ensuring the homogeneity of the participants they were exposed to Oxford Placement Test (OPT) (2007). Then, Group Embedded Figures Test (GEFT) was administered to distinguish Field Dependent and Field Independent readers. Moreover, for testing the reading ability of the students a reading comprehension test was conducted. Finally, Students Feedback Survey was distributed to both groups to evaluate their opinions regarding EFL reading comprehension. The results of the quantitative analysis of the data for via t-test revealed that there is a relationship between Field Dependency/Independency and reading comprehension. The analysis of feedback survey also denoted that Field Dependent EFL readers at intermediate proficiency level are better in understanding the main ideas and overt concepts in the text and treat reading text as a whole. While, Field Independent EFL readers at intermediate proficiency level are better in understanding the specific information, covert message in the text, inferencing, and treat reading text as a part. The pedagogical implications of the study are discussed throughout the paper.
\end{abstract}

Index Terms — field independency, field dependency, learning styles, reading comprehension, attitude

\section{INTRODUCTION}

Human beings, as supreme creatures of the world, have their own commonalities and variances, which distinguish them from other creatures in general and from one another in particular. In other words there is a commonly held view in psychology regarding these variations and differences in which, every individual is an exception. Back to what has been reverberated in the psychology; it casts some light on the dusty nature of this issue, meanwhile leaves some nuances, if not differences, to be targeted as the main topic of this study later. Field Dependency and Field Independency is one of the dichotomies of a more broad term "cognitive style" which embraces the "thinking style" and involves the way individuals think, perceive and remember information. The Field Dependence-Independence model, invented by Witkin (1977), identifies an individual's perceptive behavior while he/she is distinguishing object figures from the surrounding field in which the objects are set. In other words, in the Field-Dependent/Independent model of learning style, a Field-Independent learning style is defined as a tendency to separate details from the surrounding context, while a Field-Dependent learning style is defined as a relative inability to distinguish detail from other information around it. Field Dependence/Independence theory is one of four theories on cognitive style. Cognitive style goes back to the manner in which individuals acquire and process information. Hansen (1995) stated that "Cognitive style measures do not indicate the content of the information but simply how the brain perceives and processes the information" (p. 2). "Among the cognitive styles identified to date, the field-Dependence-Independence dimension has been the most extensively studied and has had the widest application to educational problems" (Witkin, Lewis, Hertzman, Machover, Meissner, \& Wapner, 1954; Witkin, Dyk, Faterson, Goodenough, \& Karp, 1962; Witkin, 1976, as cited in Witkin, Moore, Goodenough \& Cox, 1977, p. 1).

Moreover, the main goal of reading a text as it has been mentioned by Chastain (1975) is comprehension. However, the very failure of many reading procedures is that comprehension is not achieved adequately, if anything happens at all. It is mostly emanated from ignoring the readers who are a main part in the reading act (ibid.). The ignorance is mainly related to the readers' differences and styles of interaction with the contexts (or fields) they are reading which in turn leads them to take an attitude of reluctance toward continuing the act. This fact is even more problematic when an EFL setting is concerned where the reader must not only deal with a reading practice but also has to handle bunch of a foreign language words and structures. Whereas the willingness and engagement should be the fundamental goal of instruction, since it enhances the quality of the process and as a result the extent of comprehension (Lftody, 2006, cited 
in Salmani-Nodoushan; 2007). Two of the most widely recognized differences among the readers include Field Dependence (FD) and Field Independence (FI), an appreciation and awareness of which by both the teachers and readers can improve the comprehension of the text to a great degree. But, unfortunately, what is observed in Iranian educational settings is that the same reading procedures are conducted for the whole body of the EFL readers in the classrooms no matter what the styles of them are - i.e. how they perceive the unwritten meaning (Ellis, 2008). It is obvious that knowing how each learner acts and performs in reading comprehension and comparing them will reveal their likely weakness and strength in reading comprehension. And it also will trigger all educational stakeholders to take an appropriate approach and adapt instructional methods to cognitive style. Therefore, the present study aims to address these research questions:

1) What is the relationship between FD / FI learning styles and intermediate EFL readers' reading comprehension ability?

2) Is there any relationship between FD/FI and students' attitude toward reading comprehension in EFL reading classes?

On the basis of the aforementioned research questions these null hypotheses have been formulated:

$\mathrm{H}_{0} 1$ : There is no relationship between Field Dependency/Independency and learners' reading comprehension ability.

$\mathrm{H}_{0}$ 2: There is no relationship between FD/FI and students' attitudes towards reading comprehension.

\section{THEORETICAL AND RESEARCH BACKGROUND}

\section{A. Field Dependence/Independence Cognitive Style}

The concepts of Field Dependence (FD) and Field Independence (FI) were first introduced by Witkin and his associates in 1954 to describe individual differences in tendencies to rely primarily either on external visual cues or internal gravitational or body sensations for the perception of the upright. Later, they tried to link people's performance to their ability to visually separate an item from a complex context or field. Usually, the item was a simple geometric shape that was hidden or embedded in a more complicated drawing. In these situations, Field Independents demonstrated a greater ability to overcome a given organizational context and separate or disembed the relevant information from the surrounding stimuli; on the other hand, Field Dependents had lesser competence when performing such tasks. They viewed fields as given and performed less analysis and structuring than Field Independents.

Further studies in this area led the individual differences construct to be designated as an articulated versus global field approach and perceived as an ability to overcome embedding contexts in various perceptual and intellectual activities (Witkin et al., 1977). In the early 1960s, Witkin and his associates began to place the description of Field Dependence and independence in a broad theoretical framework of psychological differentiation that reflected the higher-order construct of self/nonself segregation and the balance of interpersonal competencies and restructuring skills (Pizzamiglio \& Zoccolotti, 1986; Witkin, Dyk, Faterson, Goodenough, \& Karp, 1962).

\section{B. Perception of Upright}

Witkin and his colleagues $(1981 ; 1954)$ summarized that (a) individuals are markedly different from each other in perceiving information and have their own preferred way of locating the upright, (b) individuals tend to be selfconsistent in their manner of reliance on external fields or bodies, (c) individuals' characteristic modes of orientation tend to remain stable over long periods of time, and (d) these characteristic modes of information processing have to be taken into consideration so as to fully understand individual's perception of the upright. In general,

Field Dependent people differ remarkably from those who are Field Independent in "how they perceive the upright, rather than in how accurately they perceive the upright" (Goodenough, 1986, p. 11). Herman A. Witkin, a worldrenowned investigator of cognitive styles, began his study of cognitive style by examining individual differences perception of the upright in space. In the late 1940s, using a Rod-Frame Test (RFT), a Body Adjustment Test (BAT), and a Rotating Room Test (RRT), Witkin and his associates undertook studies to measure subjects' variations in perception of the upright as influenced by a content field. (Witkin \& Goodenough, 1981). The question they asked was, "how important are visual cues in perceiving the vertical direction of space?" (Goodenough, 1986, p. 5). The direction of the perceived upright is primarily determined by a set of information: first, the field around us, which is usually perceived from the surrounding visual environment, and second, the direction of gravity, detected through sensations from the body. Witkin and his colleagues (Witkin \& Goodenough, 1981; Witkin et al., 1977) proposed that visual referents and body sensations both provided an accurate sense of the location of the upright, whether these two kinds of determinants were used alone or combined with each other as the referents. In the Rod-Frame Test (RFT), the subjects were required to sit in a dark room. All subjects could see was a bright square frame, within which was a luminous rod, pivoted at the center of the frame, which could be tilted either to the left side or the right side. With the frame tilted, subjects were required to adjust the rod to the upright position according to their perception. Witkin and his associates found that individuals differed dramatically in how they performed this task. For example, some of the subjects aligned the rod with the surrounding frame, no matter what the position of the frame. On the other hand, some of the subjects adjusted the rod regardless of the position of the surrounding frame. They viewed the rod as discrete from the visual frame of reference and determined the upright according to their sense of the position of the body. Another test developed to determine the role of that visual and bodily standards play in perception of the upright is the Body 
Adjustment Test (BAT). In this test, subjects were asked to sit in a small tilted room, which could be moved clockwise or counterclockwise. The chair in the tilted room could also be titled clockwise or counterclockwise but independently of the room. The subject was asked to adjust the chair from a tilted position to the upright. When the surrounding room was in a tilted position, some subjects could align themselves with the tilted room and reported that they were in a perfect upright position. Witkin and Goodenough (1981) stated, "such subjects were using the external visual field as the primary referent for perception of the upright, essentially to the exclusion of sensations from the body" (p. 9). Subjects who considered the body as the first referent for perception of the upright were able to adjust their body to the true gravitational upright. Cross (1976) reported that there was substantial correlation between RFT and BAT and that "people who ignored the tilt of the room also ignored the slant of the frame; these people were described as Field Independents. Field Dependents, on the other hand, relied consistently on the surroundings, the room, or the frame, for their orientation" (p. 117).

In the Rotating Room Test (RRT), the external field provided correct cues for subjects to perceive the upright. When there was a change in the direction of the force on the body, the visual referents remained upright. The room and the subject were rotated in a circle. The subject was asked to sit in a tilted chair within a small upright room driven around a circular track. The subject was required to adjust his or her body or the room in which he or she was seated to the upright position. If the subject believed that the postural sensations were produced by the gravity on his or her body, he or she would tilt the body and room to align with that force. On the other hand, if the subject depended more on his or her surrounding visual field, he or she would tend to identify body and room as upright in his or her initial positions. Witkin and Goodenough (1981) pointed out that the RFT and BAT depended on the internal cues of the body and led to a more accurate perception of upright. However, individuals who relied on the external field were more successful in the RRT. Individuals were consistent across all these three tests; success on the BAT and RFT was inversely related to the RRT and vice versa, which indicates that "neither a Field-Dependent nor Field-Independent mode of functioning is uniformly good or bad in their consequences for perception of the upright in space" (Witkin \& Goodenough, 1981 p. 14). Witkin et al. (1954) stated that these three tests were designed to investigate the extent to which subjects determine the upright by adherence to the axes of the visual FIELD or resist the influence of the external field through internal cues of their bodies. With these tests, the interpretation of external versus internal orientation was shown to be extended to a more general dimension of perceptual analysis called field dependence (Ramirez III \& Castaneda, 1974).

\section{Articulated versus Global Field Approach}

Further investigations on individual differences in disembedding ability expanded this research area (Witkin \& Goodenough, 1981). An articulated versus global dimension was discovered, which represents a person's ability to overcome an embedding context. This dimension focuses on the relationship between disembedding ability in perception, intellectual functioning, and structuring ability. Research evidence suggests that disembedding ability is associated in the perceptual and intellectual domains with the ability to impose structure on an unstructured field. In other words, in addition to having difficulty disembedding perceptually, Field Dependents have difficulty in solving problems that require taking a critical element for solution out of context and using it in a different context (Witkin \& Goodenough, 1981). This finding indicates that individuals perform the same level of disembedding or articulated ability across perceptual and intellectual activities, which confirmed a central hypothesis of Field Dependentindependent cognitive styles that "... individual differences in expressions of articulated functioning in one area are related to expressions in other areas ... " (Goodenough, 1976, p. 676).

Studies on the relation between disembedding and structuring ability led to an understanding that disembedding ability is related to cognitive restructuring with a perspective that there is a more "active" or more "passive" action between Field Independents and Field Dependents when they are dealing with the unstructured context. With a relatively articulated cognitive style, the individual is likely to see the parts of the field as distinct from the ground, analyze or synthesize details and parts of a figure, and examine and organize the whole structure of the field in a new way. By contrast, with a relatively global cognitive style, an individual's pattern recognition is strongly governed by field organization, and the individual experiences difficulty in distinguishing figures from the background due to a lack of restructuring ability. Instead, the individual relies more on external referents in making perceptual judgments, such as social contexts and information provided by others. Field Independents tend to experience the components of a structured field analytically, distinguish an element from a given field's organizational background, and impose structure on a field that lacks clear structure. Field dependents tend to perceive a complex stimulus globally and are more likely follow the presented visual field structure and view an unstructured field as "given". They are not good at such structuring and analytical activity (Fitzgibbons, Goldberger, \& Eagle, 1965; Ford, 2000; Goodenough, 1976; Pithers, 2002; Witkin \& Goodenough, 1981).

\section{Research in the Realm of Field Dependency and Field Independency in Iran}

In his study Salmani-Nodoushan (2007) titled "Is Field Dependence or Independence a predictor of EFL reading performance" investigated the Field Dependency or Independency on systematic variance into Iranian EFL students' overall and task-specific performance on task-based reading comprehension tests. Having selected a large number of freshman, sophomore, junior, and senior students, all majoring in English at different Iranian universities, he administered the Group Embedded Figures Test (GEFT) to the participants. His study demonstrated that individuals' 
cognitive styles made a significant difference in their test performance in the proficient, semi proficient, and fairly proficient groups, but this was not the case in the low- proficient group. In addition his study revealed that cognitive style resulted in a significant difference in participants' performance on specific tasks such as true-false, sentence completion, outlining, scanning, and elicitation in all proficiency groups.

Yarahmadi (2011) did a study on Field Independence/Dependence and ownership writing differences found that for both male and female students there was a relationship between Field Dependency and ownership in writing. She concluded that the use of first person singular pronouns and /or possessive adjectives was more characteristic of Field Dependent students. She argued that students are able to improve their writing ability by being aware of style areas in which they feel less comfortable, and this provide avenues to enrich their nonintellectual growth. In the same vain, teachers can identify learning style patterns in writing classes and make the best use of such information by devising lesson plans which takes into account individual learning style preferences.

Ahmady\&Yamini (1992) conducted a study on the relationship between Field Dependency/Independency and listening comprehension strategy use by female Iranian English language learners. Selecting, 138 students at the intermediate level, chosen out of 208, they were given the Strategy Inventory for Listening Comprehension to determine the type of strategies they used. Correlation coefficients illustrated that metacognitive, memory, cognitive and social strategies were significantly related to the cognitive style, whereas affective and compensatory strategies did not demonstrate a significant correlation. They concluded that FI students used metacognitive, memory, and cognitive strategies more frequently than the FD counterparts, but FD students used social strategies more than FI ones.

Nilforooshan \&Afghar (2007) did a study on the impact of Field Dependence-Independence in EFL learners' writing performance.They found that there is a significant difference between Field Dependent/ Independent groups in writing skill in general and narrative writing in particular with Field Independent learners outperforming the Field Dependents.

\section{Methodology}

\section{A. Participants}

This study was carried out at the University of Guilan, Rasht, Iran. Ninety undergraduate students were randomly selected in the study. They were from both genders, male and female. To ensure the homogeneity of the participants, Oxford Placement Test (OPT) (2007). Sixty students were at the intermediate proficiency level. The numbers of male and female students were 27 and 33 respectively. The participants were all in their courses of English for General Purpose, aging from 18 to 30. They were also majoring in non-English fields, such as computer software, business management, sociology, law, etc. Their mother tongue was Persian. Besides a few of them had background in the Turkish (Azari) language. All participants had the same syllabus (coursework/book) in their English classes.

\section{B. Instruments}

Four types of instruments were used in this study; Oxford Placement Test (OPT), Group Embedded Figures Test (GEFT), Reading Comprehension Test, and Students Feedback Survey. Oxford Placement Test (OPT) is an international-wide reliable and valid paper-based test (Khalili\& Mahsefat, 2012) administered to determine the proficiency level of the participants. This placement test consisted of 50 multiple choice items assessing students' knowledge of key grammar and vocabulary from elementary to intermediate levels, a reading text followed by 10 comprehension questions and also an optional writing task that aimed to assess students' ability to produce the language. The time allotted for this test was 65 minutes. According to its manual, it enables teachers to have a better understanding of their students' English proficiency level; moreover its manual serves its scoring. There are two tools here. The first are those to distinguish between FD and FI students and the second are those to collect data from the field. The distinguishing tools comprise Group Embedded Figures Test (GEFT) developed for the first time by Witkin (1948). In the test, learners are asked to find the simple figure(s) embedded in a relatively complex figure. What would appear is that the Field-Independent individuals can omit the influence of the background image and find the hidden figure, while those who are Field-Dependent will have difficulty in completing the task. Reading Comprehension Test was made up of 50 multiple-choice questions which is a reliable and valid test used as a proficiency test. By the same token, as this test is taken from TOEFL, its validity and reliability has been warranted. Finally, the students were given a chance to provide feedback as far as their styles they were explored. The instructor administered a Student Feedback Survey which contained a series of questions to generate the students' opinions on reading ability, (See the appendix). It is a Likert-based scale questionnaire which asks a series of questions from both Field Dependent and Field Independent. The results of the survey provided valuable information that helped explain the conclusions of the study. The questionnaire consisted of 20 multiple-choice question designed to collect information related to their ideas and opinions about reading. It was covered with a consent form, which informed the participants that completing the questionnaire meant that they consented to participate in the study. To avoid any misunderstanding on the part of the students, the questionnaire was translated into Persian, the participants' mother tongue. In order to guarantee its reliability and validity it was piloted to a group of thirty students similar to the participants and its reliability was reported as acceptable $(\mathrm{r}=0.61)$.

\section{Procedure}


This study aimed to determine the probable relationship between of both learning styles of Field (In) Dependent and reading comprehension of intermediate EFL readers. For this purpose, 90 students randomly were selected. Oxford Placement test was administered to determine the proficiency level of students. Having administered the test, 60 students were selected. They were at intermediate level. In order to check their learning styles, Group Embedded Figures Tests (GEFT) was administered to determine the students' styles namely, Field Dependency and Field Independency. Before administering reading comprehension test, the Field Dependent and Field Independent students were determined and placed in separate groups. The number of Field Dependent and Field Independent learners was 36 and 24 respectively. After that, the reading comprehension test was administered to identify students' knowledge of reading to pave the way for further comparison. The data (scores) taking from two groups of participants were analyzed. The raw data of the tests were analyzed by SPSS Software (version 19). For the purpose of comparing the mean scores of the two groups, several $t$-tests were run. Then Paired Samples tests were run to determine the degree of progress made by each group. To achieve this goal, the means of scores were compared and analyzed through paired samples $\mathrm{t}-$ test. The results revealed that there was a relationship among variables. To determine whether there was a significant difference, level of alpha $(\alpha)$ was set to 0.05 .

\section{RESULTS}

In the subsequent sections, the results of the statistical analyses of the data will be presented.

\section{A. The Results of Reading Comprehension Test}

In this section the results of Paired Samples Statistics, Paired Samples Correlations and Group statistics for comparison of FI and FD scores in reading comprehension test are reported. Paired Samples Statistics shows the descriptive statistics, mean, number, standard deviation, standard error of mean.

TABLE1

PAIRED SAMPLES STATISTICS

\begin{tabular}{|ll|l|l|l|l|}
\hline & Mean & N & Std. Deviation & Std. Error Mean \\
\hline \multirow{2}{*}{ Pair 1 } & score FD & 23.04 & 36 & 5.284 & 0.881 \\
& score FI & 27.08 & 24 & 6.769 & 1.382 \\
\hline
\end{tabular}

TABLE2

PAIRED SAMPLES CORRELATIONS

\begin{tabular}{|ll|l|l|l|}
\hline & $\mathrm{N}$ & Correlation & Sig. \\
\hline Pair 1 & FD score\& FI score & 60 & .029 & .891 \\
\hline
\end{tabular}

Paired Samples Correlations denotes the correlation between Field Dependency and Field Independency. The range of correlation is between 1 and -1 .

TABLE 3

GROUP STATISTICS FOR COMPARISON OF FI AND FD SCORES IN READING COMPREHENSION TEST

\begin{tabular}{|c|c|c|c|c|c|c|c|c|c|}
\hline & & \multicolumn{5}{|c|}{ Paired Differences } & \multirow[b]{3}{*}{$\mathrm{t}$} & \multirow[b]{3}{*}{ df } & \multirow{3}{*}{$\begin{array}{l}\text { Sig. (2- } \\
\text { tailed) }\end{array}$} \\
\hline & & \multirow[b]{2}{*}{ Mean } & \multirow[b]{2}{*}{ Std. Deviation } & \multirow{2}{*}{ Std. Error Mean } & \multicolumn{2}{|c|}{$\begin{array}{l}95 \% \text { Confidence Interval of the } \\
\text { Difference }\end{array}$} & & & \\
\hline & & & & & Lower & Upper & & & \\
\hline Pair 1 & $\begin{array}{l}\text { FD score \& } \\
\text { FI score }\end{array}$ & -4.042 & 8.291 & 1.692 & -7.543 & -.541 & -2.388 & 23 & .126 \\
\hline
\end{tabular}

In this section as it can be seen in the output data of the performance of the both Field In/Dependent groups in reading comprehension test, there is difference between the Field dependent group and the Field Independent group regarding their reading comprehension score. The Mean of the Field Independent group is $\mathbf{2 7 . 0 8}$ and the mean of the Field Dependent group is $\mathbf{2 3 . 0 4}$. Therefore, in order to verify whether this difference is statistically significant or not, the data were analyzed via SPSS software program (version 19) to compare the means of the two groups by means of running a Samples T-test. The result of the test revealed that there is statistically significant difference between the means of the Field Independent group and Field Dependent group at the level of $\alpha=0.05$. The conclusion is that the two groups are different in terms of reading comprehension. It can be claimed that the Field Independent group and the Field Dependent group are different in terms of related proficiency. As the tables demonstrate the distribution difference between two variable Field dependency/Field Independency and reading comprehension mean, standard deviation and standard error of mean have been shown. The interval confidence is $\mathbf{9 5 \%}$ and $t$ is-2.388( $\mathbf{t}=\mathbf{- 2 . 3 8 8})$. Since the value of significant amount of $\mathrm{t}(\mathbf{0 . 1 2 1})$ is higher than the assumed level of significance (0.05), the hypothesis is rejected. In other words it is concluded that there is a relationship between Field In/Dependency and reading comprehension.

\section{B. The Results of Students' Feedback Survey}

Besides the empirical data which were collected, and the statistical analyses carried out in the current study, the opinions of the participants of the present study also provided valuable insights regarding their Field Independency and 
Field Independency. A survey was conducted on the students' perceptions, with regard to the Field Independency and Field Independency. This feedback survey was developed and piloted by the authors before conducting the study, it was culturally adapted and statically tested to warrant test reliability $(\mathrm{r}=0.61)$.

TABLE4

DESCRIPTIVE STATISTICS OF FIELD DEPENDENT GROUP STUDENTS' FEEDBACK SURVEY

\begin{tabular}{|c|c|c|c|c|c|c|c|c|c|c|}
\hline & SA & $\%$ & A & $\%$ & D & $\%$ & SD & $\%$ & Mean & Std. D \\
\hline 1 & 13 & 36.1 & 15 & 41.7 & 3 & 8.3 & 5 & 13.9 & 2.00 & 1.014 \\
\hline 2 & 19 & 52.8 & 10 & 27.8 & 2 & 5.6 & 5 & 13.9 & 1.81 & 1.064 \\
\hline 3 & 3 & 8.3 & 7 & 19.4 & 18 & 50.0 & 8 & 22.2 & 1.86 & 0.867 \\
\hline 4 & 14 & 38.9 & 6 & 16.7 & 12 & 33.3 & 4 & 11.1 & 2.17 & 1.082 \\
\hline 5 & 15 & 41.7 & 11 & 30.6 & 7 & 19.4 & 3 & 8.3 & 1.94 & 0.984 \\
\hline 6 & 1 & 8.3 & 7 & 19.4 & 5 & 13.9 & 23 & 58.3 & 3.22 & 1.045 \\
\hline 7 & 11 & 30.6 & 13 & 36.1 & 8 & 22.2 & 4 & 11.1 & 2.14 & 0.990 \\
\hline 8 & 2 & 5.6 & 2 & 5.6 & 10 & 27.8 & 22 & 61.1 & 3.44 & 0.843 \\
\hline 9 & 17 & 47.2 & 7 & 19.4 & 6 & 16.7 & 6 & 16.7 & 2.03 & 1.0158 \\
\hline 10 & 19 & 38.9 & 15 & 41.7 & 1 & 8.3 & 1 & 8.3 & 2.11 & 1.116 \\
\hline 11 & 16 & 44.4 & 12 & 33.3 & 2 & 5.6 & 6 & 16.7 & 1.94 & 1.094 \\
\hline 12 & 9 & 25 & 12 & 33.3 & 12 & 33.3 & 3 & 8.3 & 2.25 & 0.937 \\
\hline 13 & 10 & 27.8 & 10 & 27.8 & 13 & 36.1 & 3 & 8.3 & 2.25 & 0.967 \\
\hline 14 & 8 & 22.2 & 6 & 16.7 & 12 & 33.3 & 10 & 27.8 & 2.69 & 1.231 \\
\hline 15 & 7 & 19.4 & 2 & 5.6 & 14 & 38.9 & 13 & 36.1 & 2.92 & 1.105 \\
\hline 16 & 3 & 8.3 & 2 & 5.6 & 12 & 33.3 & 19 & 52.8 & 3.31 & 0.920 \\
\hline 17 & 12 & 33.3 & 15 & 41.7 & 7 & 19.4 & 2 & 5.6 & 1.97 & 0.878 \\
\hline 18 & 12 & 33.3 & 18 & 50.0 & 4 & 11.1 & 2 & 5.6 & 1.92 & 0.906 \\
\hline 19 & 20 & 55.6 & 9 & 25 & 6 & 16.7 & 1 & 2.8 & 1.67 & 0.863 \\
\hline 20 & 1 & 2.8 & 5 & 13.9 & 11 & 30.6 & 19 & 52.8 & 3.3 & 0.828 \\
\hline
\end{tabular}

The survey contained 20 multiple-choice questions (appendix A). The participants who completed the questionnaire were unanimously Field Dependent (code, 1). The mean, standard deviation, frequency of each answer for each question has been depicted in the table. Questions $(2,4,9,17,18,19)$ which directly aim the Field Dependent participants' attitudes toward reading comprehension and their preferences received high numerical value for mean score $(\mathrm{mean}=2.5$ and $\mathrm{p}=50 \%$ ). Similarly, questions $(5,9,17)$ received the highest mean score ( $m e a n=2.30$ and $\mathrm{p}=60 \%$ ). Question 2 asks about the main idea, around $80 \%$ of Field Dependents participants believe they could understand the main idea easily. Question 3 asks about finding the supporting paragraphs, the analysis shows that about 30\% of the Field Dependent participants could understand the relations and main idea supporting paragraphs. Around $70 \%$ of them stated that they could not easily identify the supporting paragraphs. More than $75 \%$ of the Field Dependent students pointed that they can easily understand the main idea. Field dependents by definition can understand whole before parts. Therefore, the result illuminates that Field Dependents are better in understanding the main idea of the text. Regarding the concentration on text and text analysis less than $25 \%$ could concentrate easily, around $75 \%$ of the participants could not easily concentrate and analyze the text. More than $85 \%$ of the Field Dependent participants told that they have problem in understanding the concepts and contexts which are implicitly stated in the text. Regarding guess-making, one of the most preferable techniques by participants, enjoys $80 \%$. Finally, the texture understanding and getting the covert ideas, which has the lowest preference among Field Dependent participants, only $20 \%$ of the Field Dependents said they can cope with such complexity, around $80 \%$ of them stated that they have problems in understanding covert ideas and concepts. Similarly, as it was expected, more than $75 \%$ of them pointed out that they could favorably deal with the clear cut questions and concept in the text. The findings of the survey revealed that the Field Dependent group responded favorably on the questions regarding understanding the main idea, understanding the general message behind the text, guess-making.

They exerted a higher level of satisfaction with these questions and enjoyed higher frequency and mean. The percentages explicate that the Field Dependent group scored higher in following variables, such as texture understanding, getting the overt ideas, understanding the general message behind the text, guess-making. The results of this survey confirmed that Iranian Field Dependent EFL learners at intermediate proficiency level are better in understanding the main ideas and overt concepts in the text and treat reading text as a whole. 
TABLE 5

DESCRIPTIVE STATISTICS OF FIELD INDEPENDENT GROUP STUDENTS' FEEDBACK SUR VEY

\begin{tabular}{|c|c|c|c|c|c|c|c|c|c|c|}
\hline & SA & $\%$ & A & $\%$ & $\mathrm{D}$ & $\%$ & SD & $\%$ & Mean & Std. D \\
\hline 1 & 12 & 50.0 & 5 & 20.8 & 6 & 25 & 1 & 4.2 & 2.8 & 1.1 \\
\hline 2 & 3 & 12.5 & 4 & 16.7 & 12 & 50 & 5 & 20.8 & 2.79 & 0.932 \\
\hline 3 & 12 & 50 & 7 & 29.2 & 3 & 12.5 & 2 & 8.3 & 1.79 & 0.977 \\
\hline 4 & 6 & 25 & 6 & 25 & 6 & 25 & 6 & 25 & 2.5 & 1.142 \\
\hline 5 & 8 & 33 & 7 & 29.2 & 6 & 25 & 3 & 12.5 & 2.17 & 1.049 \\
\hline 6 & 12 & 50 & 7 & 29.2 & 4 & 16.6 & 1 & 4.2 & 1.75 & 0.897 \\
\hline 7 & 15 & 62.5 & 7 & 29.2 & 1 & 4.2 & 1 & 4.2 & 1.5 & 0.897 \\
\hline 8 & 12 & 50 & 8 & 33 & 2 & 8.3 & 2 & 8.3 & 1.75 & 0.944 \\
\hline 9 & 6 & 25 & 6 & 25 & 6 & 29.2 & 6 & 25 & 2.54 & 1.103 \\
\hline 10 & 7 & 29.2 & 7 & 29.2 & 4 & 16.6 & 6 & 25 & 2.38 & 1.173 \\
\hline 11 & 2 & 8.3 & 6 & 25 & 10 & 41.7 & 6 & 25 & 2.83 & 0.917 \\
\hline 12 & 5 & 20.8 & 9 & 37.5 & 6 & 25 & 4 & 16.7 & 2.38 & 1.013 \\
\hline 13 & 7 & 29.2 & 5 & 20.8 & 2 & 8.3 & 10 & 41.7 & 2.63 & 1.313 \\
\hline 14 & 2 & 8.3 & 7 & 29.2 & 11 & 45.8 & 4 & 16.7 & 2.71 & 0.895 \\
\hline 15 & 14 & 58.3 & 6 & 25 & 2 & 8.3 & 2 & 8.3 & 1.67 & 0.963 \\
\hline 16 & 18 & 75 & 2 & 8.3 & 1 & 4.2 & 3 & 12.5 & 1.54 & 1.067 \\
\hline 17 & 10 & 41.7 & 3 & 12.5 & 7 & 29.2 & 4 & 16.7 & 2.21 & 1.179 \\
\hline 18 & 3 & 12.5 & 2 & 8.3 & 12 & 50 & 7 & 29.2 & 2.96 & 0.955 \\
\hline 19 & 3 & 12.5 & 4 & 16.7 & 13 & 54.2 & 4 & 16.7 & 2.75 & 0.897 \\
\hline 20 & 13 & 54.2 & 7 & 29.2 & 3 & 12.5 & 1 & 4.2 & 1.67 & 0.868 \\
\hline
\end{tabular}

By the same token, the questionnaire was administered to Field Independent group (code, 2). The mean, standard deviation, frequency of each answer for each question has been depicted in the table. Questions $(3,6,15,16,20$,$) which$ directly address the Field Independent participants' attitudes toward reading comprehension and their preferences received high numerical value for mean score (mean $=1.7$ and $\mathrm{p}=50 \%$ ). Similarly, questions $(6,8,16)$ received the highest mean score (mean $=3.30$ and $\mathrm{p}=60 \%$ ). Question 3 asks about finding the supporting paragraphs, the analysis shows that more than $70 \%$ of the Field Independent participants could understand the relations and main idea supporting paragraphs. Around $70 \%$ of them stated that they could easily identify the supporting paragraphs. Around $80 \%$ of the Field Independent students pointed that they can easily concentrate on the text. Field Independents by definition can understand parts before whole. Therefore, the result illuminates that Field Independents are better in understanding the inter-textual concept. $90 \%$ of the Field Independent participants told that they can understand the concepts and contexts which are implicitly stated in the text. In other words, the results show that Field Independent can infer better $(\mathrm{p}=75 \% \mathrm{M}=2.8)$. Finally, it is the texture understanding and getting the covert ideas, which has the highest preference among Field Independent participants (mean $=1.54 \mathrm{p}=85 \%$ ). The findings of the survey revealed that the Field Independent group responded favorably on the questions regarding understanding the covert idea, understanding the specific information lied behind the text, inter-textual relationship. They exerted a higher level of satisfaction with these questions and enjoyed higher frequency and mean. The percentages denote that the Field Independent group scored higher in the following variables, such as understanding specific and exceptional concept, getting the covert ideas, and inferencing. The results of this survey confirmed that Iranian Field Independent EFL learners' at intermediate proficiency level, are better in understanding the specific information, covert message in the text, inferencing, and treat reading text as a part.

\section{DisCUSSION AND CONCLUSION}

The findings of this study are in congruence with what was reported by numerous experts in the past. (Witkin \& Goodenough, 1981;Messick, 1976; Witkin et al., 1977;Davis \&Cochran, 1990; Witkin et al., 1977;Thompson \&Thompson,1987;Davis ,1991;Goodenough,1976; Davey and Menke, 1989;Luk, 1998;Ahmady\&Yamini, 1992 ).There exists a relationship between FIELD Dependency / Independency and reading comprehension. The obtained results might be attributed to some factors. In our view, one of the probable causes could be the fact that cognitive styles affect learning in students. (Messick, 1976).

Regarding the second hypothesis, there are different opinions between Field Dependent and Field Independent EFL learners towards reading comprehension. The second view is that students with varying cognitive styles are different due to the fact that their psychological demands and preferences and their potentials are different. The rationale for relationship is likely that, the participants might have different initiatives and psychological capability to benefit from the facilitative and natural feature such as redundancy, extra linguistic factors etc. of the texts to comprehend their contents. As Davey \&Menke (1989) and Cochran \&Davis, (1987) asserted Field Independent readers might have better comprehension abilities because of their higher cognitive skills in areas such as organization of knowledge recall, use of context cues, use of imagery, and active hypotheses-test behaviors. In line with Jones, (1993) Field Independent focus their attention on task-relevant information and ignore distractions better than Field Dependent individuals (Davis \&Cochran, 1990). Field Independents who approach a field in an analytical way and extract elements from its complex background have greater disembedding ability in perceptual functioning and better cognitive restructuring than Field dependents. Also, we can come up with another plausible justification to account for the impact of cognitive styles on 
the basis of Witkin's characterization of cognitive styles. In his contention, inclination to separate details from the surrounding context is pragmatically plausible rationale sense that exemplifies a contextually appropriate use of Field Dependency and Field Independency in the text recognition and perception. It seems that the results taken from this study, cast light on the Field's statement accordingly, as it was reiterated in previous study (Davis, 1991; Goodenough, 1976; Davey \&Menke, 1989; Luk, 1998).

\section{APPENDIX}

$$
\text { دانشجويان كر امى درى }
$$

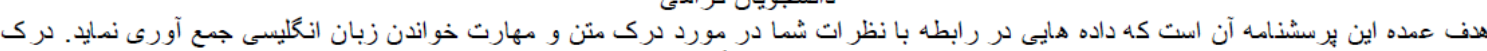

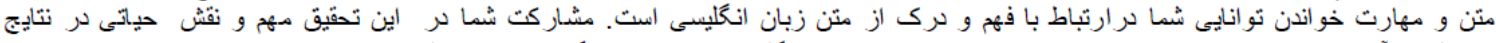

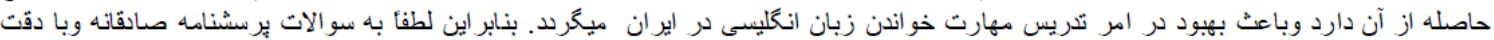

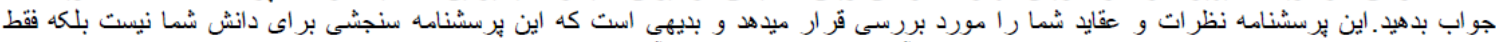

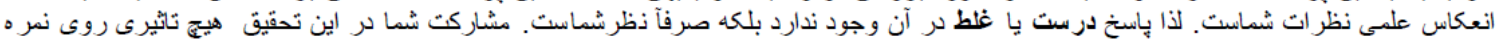

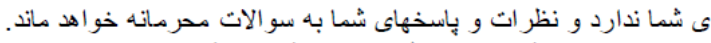

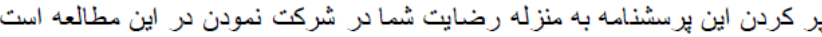

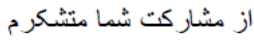

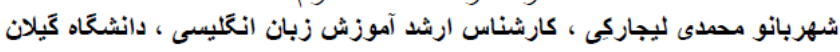

$$
\begin{aligned}
& \text { قسمت اول : اطلاعات كلى }
\end{aligned}
$$

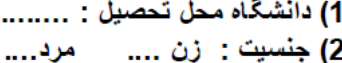

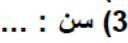

$$
\begin{aligned}
& \text { 4) كد كلاس : :............ }
\end{aligned}
$$

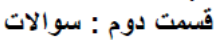

$$
\begin{aligned}
& \text { لطفاً بك كَزينه را انتخاب كنيد. }
\end{aligned}
$$

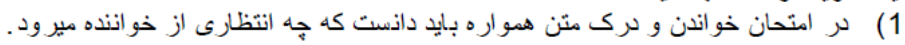

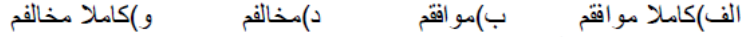

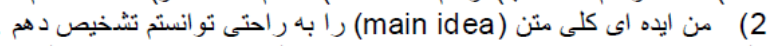

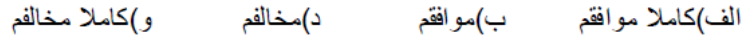

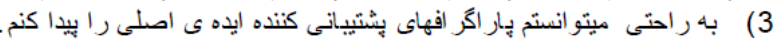

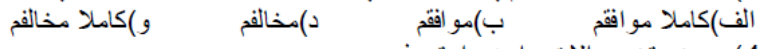

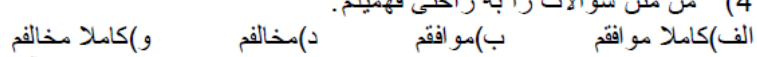

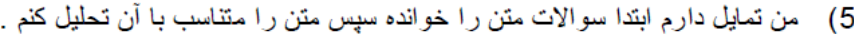

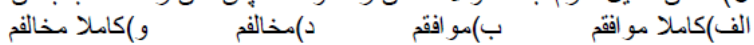

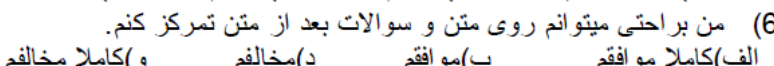

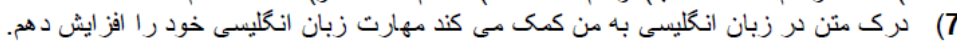

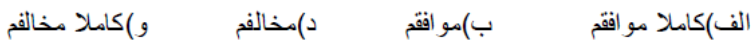

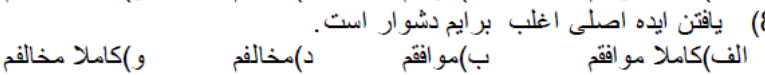

$$
\begin{aligned}
& \text { 9) با كذشت زماند موافم درى من از سوالات بهتر ميشود. }
\end{aligned}
$$

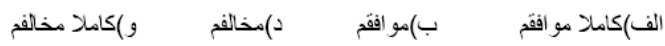

$$
\begin{aligned}
& \text { 10) من از تمرينات ريلكسيثن وتكنيك هاى مثَبه در امنحان درك مطلب استفاده ميكنم. }
\end{aligned}
$$

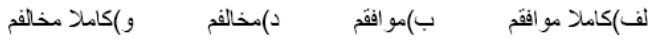

$$
\begin{aligned}
& \text { 11) اصلا نمركز واحساس خوبى موقع امتحان درك مطلب ندارم. }
\end{aligned}
$$

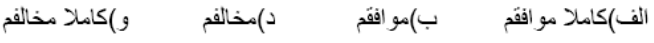

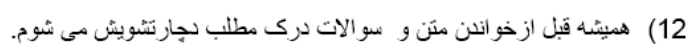

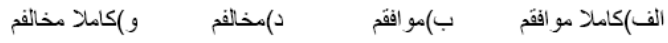

$$
\begin{aligned}
& \text { 13) من هميُّه سر جلسه امتحان و بعد امتحان درك منَن افسوس ميخور كاش بيُشتر تلاش ميِكردم. }
\end{aligned}
$$

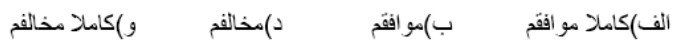

$$
\begin{aligned}
& \text { 14) درك متن و مطلب بنيار مهم است. }
\end{aligned}
$$

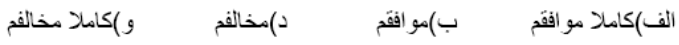

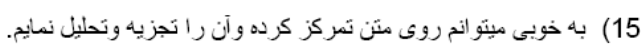

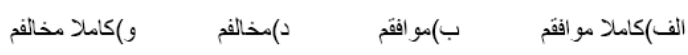

$$
\begin{aligned}
& \text { 16) در دريافتن مفاهيمى كه به صورت يوشيده وضمنى به آنها انثار ه شده مشكلى ندارم. }
\end{aligned}
$$

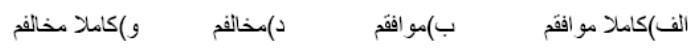




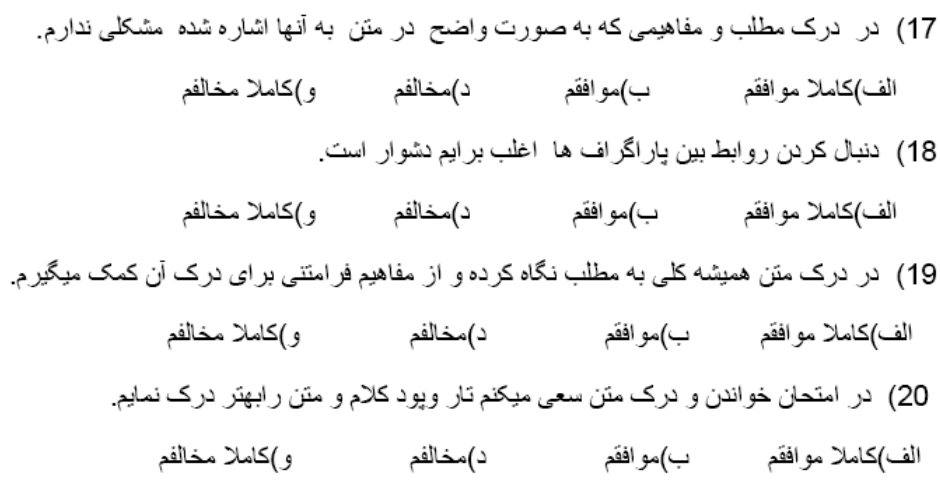

\section{REFERENCES}

[1] Ahmady, A., Yamini, M. (1992). Relationship between field dependence/independence and listening comprehension strategy use by female Iranian English Majors. Cultural studies and humanities research, 5, 62-75.

[2] Chastain, K. (1975). Developing second language, London, UK: Oxford University Press.

[3] Cochran, K. F., \& Davis, L. K. (1987). Individual differences in inference processes. Journal of Research in Personality, 21, 197-210.

[4] Cross, K. P. (1976). Accent on learning: Improving instruction and reshaping the curriculum. San Francisco, CA: Jossey-Bass.

[5] Davey, B., \& Menke, D. (1989). The importance of cognitive style in children's acquisition of reading skill. Early Child Development and Care, 51, 49-64.

[6] Davis, L. K. (1991). Educational implications of field-dependence-independence. In A. Wapner \& J. Demick (Eds.), Field dependence-independence: Cognitive style across the life span (pp. 149-176). Hillsadle, NJ: Lawrence Erlbaum Associates.

[7] Davis, L. K., \& Cochran, K. F. (1990). An information processing view of field dependence independence. In O. N. Saracho (Ed.), Cognitive style in early education (pp. 61-78). New York: Gordon and Breath Science.

[8] Ellis, R. (2008). The study of second language acquisition. $2^{\text {nd }}$ ed., Oxford: Oxford university press.

[9] Fitzgibbons, D. J., Goldberger, L., \& Eagle, M. (1965). Field dependence and memory for incidental material. Perceptual and Motor Skills, 21, 743-749.

[10] Ford, N. (2000). Cognitive styles and virtual environments. Journal of the American Society for Information Science, 51(6), 543-557.

[11] Goodenough, D. R. (1976). The role of individual differences in field dependence as a factor in learning and memory. Psychological Bulletin, 83(4), 675-694.

[12] Goodenough, D. R. (1986). History offield dependent construct. In M. Bertini \& L. Pizzamiglio \& S. Wapner (Eds.), Field dependence in psychological theory, research, and application: Two symposia in memory of Herman A. Witkin (pp. 5-14). Hillsdale, NJ: Lawrence Erlbaum Associates.

[13] Hansen, J. (1995). The Relationship of Field Dependent/Independent Cognitive Styles to Foreign Language. Language Learning, 31(2), 49-67.

[14] Jones, S. (1993). Cognitive learning styles: Does awareness help? A review of selected literature. Language Awareness, 2(4), 195-207.

[15] Khalili. M, \& Mahsefat, H. (2012). The Impact of authentic listening materials on elementary EFL learners' listening skills. International of Journal of Applied Linguistic and Literature, 1(4), 216-229.

[16] Luk, S. C. (1998). The relationship between cognitive style and academic achievement. British Journal of Educational Technology, 29(2), 137-147.

[17] Messick, S. (1976). Personality consistencies in cognition and creativity. In S. Messick \& Associates (Eds.), Individuality in learning (pp. 4-22). San Francisco: Jossey-Bass.

[18] Nilforooshan. N., \& Afghari, A. (2007). The Effect of Field Dependence-Independence as a Source of Variation in EFL Learners' Writing Performance. Iranian Journal of Language Studies (IJLS), Vol. 1(2), 58-70.

[19] Pithers, R. T. (2002). Cognitive learning style: A review of the field dependent-field independent approach. Journal of Vocational Education \& Training, 54(1), 117-132.

[20] Pizzamiglio, L., \& Zoccolotti, P. (1986). Individual differences: Cerebral structure and cognitive characteristics. In M. Bertini \& L. Pizzamiglio \& S. Wapner (Eds.), Field dependence in psychological theory, research, and application (pp. 27-44). Hillsdale, NJ: Lawrence Erlbaum Associates.

[21] Ramirez, M., \& Castaneda, A. (1974). Cultural democracy, bicognitive development and education. New York: Academic Press.

[22] Salmani-Nodoushan, M., A., (2007). Is field dependence or independence a predictor of EFL reading performance TESL Canada Journal, 24(2), 82-108.

[23] Thompson, M. E., \& Thompson, M. E. (1987, February). Field dependence-independence and learning from instructional text. Paper presented at the annual meeting of the Association for Educational Communications and Technology, Atlanta, GA.

[24] Witkin, H.A. (1967). A cognitive approach to cross-cultural research. International Journal of Psychology 2(4), $233-250$.

[25] Witkin, H.A., Moore, C.A., Goodenough, D.R. \& Cox, P.W. (1977). Field- dependent and field-independent cognitive styles and their educational implications. Review of Educational Research 47(1), 1-64.

[26] Witkin, H.A., \& Goodenough, D.R. (1981). Cognitive styles: Essence and origin. New York: International Universities Press. 
[27] Witkin, H. A., Dyk, R. B., Faterson, H. F., Goodenough, D. R., \& Karp, S. A. (1962). Psychological differentiation. New York: John Wiley \& Sons.

[28] Witkin, H. A., Moore, C. A., Goodenough, D. R., \& Cox, P. W. (1977). Field-dependent and field-independent cognitive styles and their educational implications. Review of Educational Research, 47(1), 1-64.

[29] Yarahmadi, M., (2011). Field independence/dependence and ownership writing differences. Journal of basic and applied scientific research, 1(12), 2734-2735.

Masoud Khalili Sabet is Assistant Professor of TEFL and the assistant director of research and technology at University of Guilan, Rasht, Iran. His research interests include advanced writing, methodology of language teaching, language teaching in practice, and testing.

Shahrbanoo Mohammadi is an M.A. student of TEFL at University of Guilan. Her area of research interest is language skills and components and cognitive psychology. 